\title{
Spontaneous Subarachnoid Hemorrhage in a Patient with a Co-Existent Posterior Communicating Artery Aneurysm and Cervical Spine Aneurysm Associated with Ventral Arterio-Venous Fistula
}

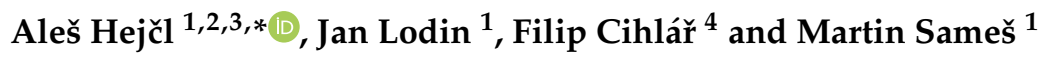 \\ 1 Department of Neurosurgery, J.E. Purkinje University, Masaryk Hospital, Sociální péče 12A, \\ 40113 Ústí nad Labem, Czech Republic; jan_lodin@hotmail.com (L.J.); martin.sames@kzcr.eu (M.S.) \\ 2 International Clinical Research Center, St. Anne's University Hospital, 38975 Brno, Czech Republic \\ 3 Institute of Experimental Medicine, Academy of Sciences of the Czech Republic, Vídeňská 1083, \\ 14220 Prague, Czech Republic \\ 4 Department of Radiology, J. E. Purkinje University, Masaryk Hospital, 40113 Ústí nad Labem, \\ Czech Republic; filip.cihlar@kzcr.eu \\ * Correspondence: ales.hejcl@gmail.com; Tel.: +420-777-232-793; Fax: +420-477-112-880
}

Received: 16 January 2020; Accepted: 23 January 2020; Published: 28 January 2020

\begin{abstract}
Severe spontaneous subarachnoid hemorrhage (SAH) is predominantly caused by aneurysm rupture, with non-aneurysmal vascular lesions representing only a minority of possible causes. We present the case of a 58-year old lady with a coincidental posterior communicating artery (PCom) aneurysm and a high cervical spine arterio-venous fistula associated with a small ruptured aneurysm. After the emergency clipping of the PCom aneurysm, additional diagnostic procedures-repeated digital subtraction angiography and spinal magnetic resonance imaging, revealed the actual cause of the SAH, a type-A ventral intradural fistula at cervical level C2/3. The fistula was treated micro surgically via a ventral approach using C3 somatectomy and C2-4 stabilization after the initial failure of endovascular therapy. Furthermore, the patient was treated for complications associated with severe $\mathrm{SAH}$, including acute hydrocephalus and meningitis. In cases where the SAH pattern and perioperative findings do not suggest an intracranial aneurysm as the source of SAH, further diagnostic investigation is warranted to discover the real cause. Patients with severe non-aneurysmal $\mathrm{SAH}$ require a similar algorithm in diagnosing the cause of the hemorrhage as well as complex conditions such as ruptured aneurysms.
\end{abstract}

Keywords: subarachnoid hemorrhage; spinal AV fistula; aneurysm; hydrocephalus

\section{Introduction}

Spontaneous subarachnoid hemorrhage (SAH) is caused by an intracranial aneurysm rupture in $85 \%$ of cases [1]. Concurrently, there has been an increasing incidence of patients with non-aneurysmal SAH [2]. Non-aneurysmal SAH can be divided into perimesencephalic SAH (PMSAH) and non-perimesencephalic SAH (non-PMSAH). While patients with PMSAH, in general, seem to have good outcomes with a minimal chance of an undisclosed lesion diagnosis on initial digital subtraction angiography (DSA), about $12 \%$ of patients with non-PMSAH have a cranial or spinal lesion responsible for the SAH [3]. Spinal arterio-venous fistulas (AVFs) are rare lesions, which usually present with pain, paralysis, or paresthesias, however, about $9 \%$ may also present with SAH [4]. In this study, we present the case of a patient who suffered severe SAH and harbored a ruptured ventral intradural cervical AVF with an associated aneurysm and coincidental, right posterior communicating artery (PCom) 
aneurysm. We demonstrate our diagnostic approach and treatment of the lesion itself as well as the complications associated with $\mathrm{SAH}$ in such a rare case.

\section{Case Report}

A 58-year old nurse experienced a sudden severe nuchal headache at home. After an ambulance arrived, she lost consciousness (Glasgow Coma Scale, GCS 7). She was intubated, sedated, and transferred to the local hospital. The emergency computed tomography (CT) scan showed a massive subarachnoid hemorrhage predominantly located in the basal cisterns, posterior fossa (pretruncal), and in the ventral spinal canal down to level C5 (Figure 1A,B). CT angiography (CTA) showed an aneurysm located on the PCom with an inferiorly directed sac and no other source of hemorrhage (Figure 1C). The patient was transferred to our hospital, after necessary preparation at the Emergency Department she was taken acutely into the operating room, where extra ventricular drainage (EVD) was implanted, and the aneurysm was secured with two stacked, slightly curved $5 \mathrm{~mm}$ clips from a right lateral supraorbital craniotomy [5,6]. However, further inspection of the aneurysm under the operating microscope showed no signs of its rupture. The patient was extubated the following day, and a postoperative CT showed no signs of complications (hemorrhage, ischemia) as well as confirming complete exclusion of the PCom aneurysm (Figure 1D). Due to the massive subarachnoid hemorrhage in front of the brain stem, with significant extension in the spinal canal and no clear sign of aneurysm rupture during surgery, we performed cerebral DSA on the third day after clipping. Angiography confirmed the complete exclusion of the aneurysm with no other source of hemorrhage. Still, we were not satisfied with the diagnostic result and therefore, planned a check-up angiography three weeks after the initial SAH. During the initial 14 days following hemorrhage, the patient was monitored at the Intensive Care Unit. The patient was extubated on the fourth day after surgery. As the patient was dependent on the EVD, we exchanged the EVD on Day 9 for a lumbar drain. As the patient repeatedly proved to be drain-dependent, we were forced to implant a ventriculo-peritoneal (VP) shunt. Unfortunately, two revisions of the shunt were necessary due to its malposition the following day. We removed the VP shunt 4 days later because the patient contracted meningitis despite antibiotic therapy. The patient was monitored for cerebral vasospasms with repeated transcranial dopplerometry (TCD). No vasospasms were detected. 

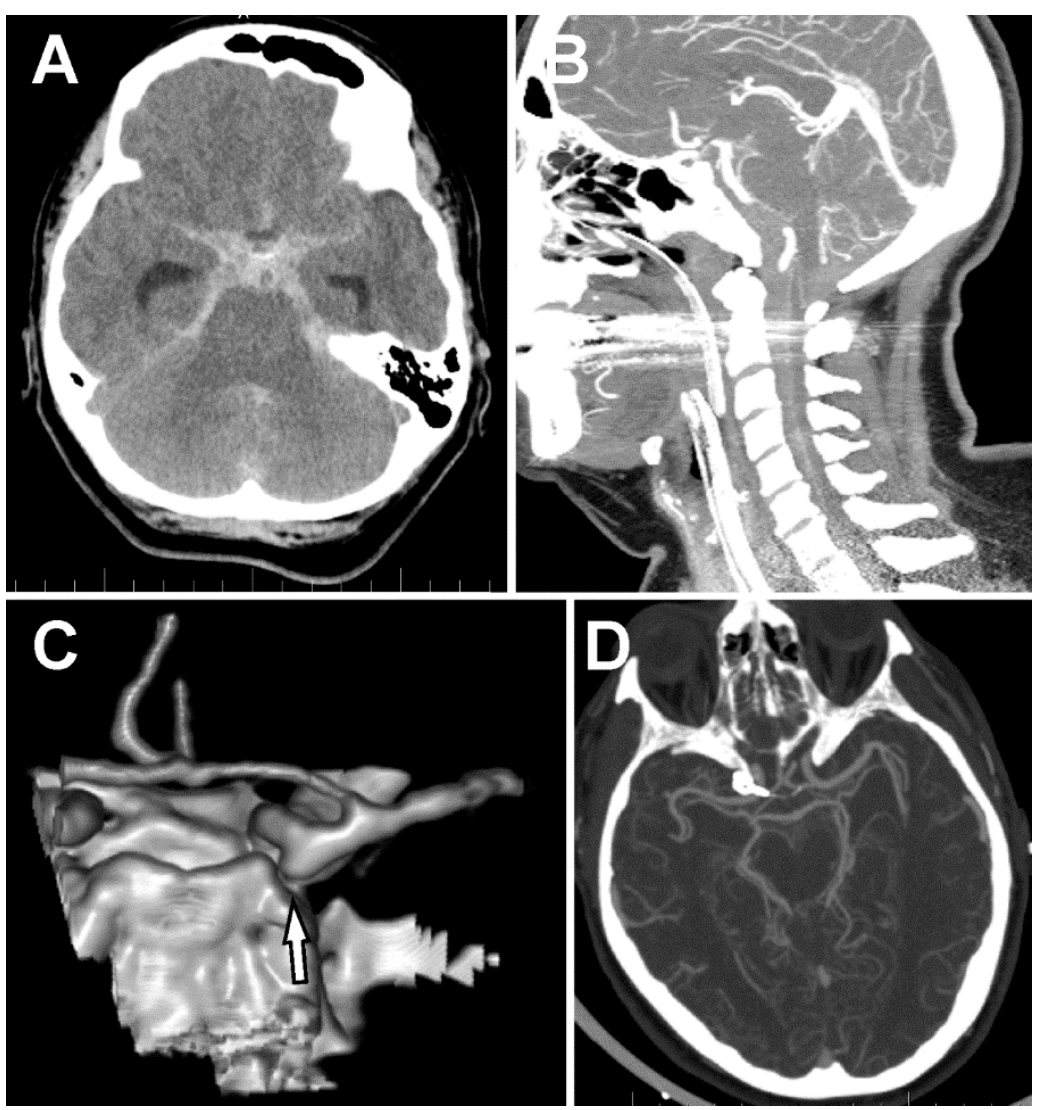

Figure 1. Subarachnoid hemorrhage and the posterior communicating artery (PCom) aneurysm. (A) Massive spontaneous subarachnoid hemorrhage (SAH) in the basal cisterns and both Sylvian cisterns. (B) SAH in front of the brain stem and the ventral subarachnoid space all the way down to C6. (C) 3D-CT angiography (CTA) showing an aneurysm of the right PCom artery directing downward to the posterior fossa. (D) CTA after clipping of the PCom artery.

The follow-up angiography revealed a small ventral arterio-venous fistula associated with a small aneurysm at cervical level C2/3. It was a type III AV fistula, according to Kim and Spetzler [7], and a type IVa based on the classification of Heros [8] (Figure 2A). It was fed by a sulcal artery from the anterior spinal artery (ASA). A subsequent cervical spine MRI confirmed a left paramedian lesion ventral to the spinal cord at the level of the $\mathrm{C} 2 / 3$ intervertebral disc (Figure 2B). The patient was prepared for an endovascular procedure. The right vertebral artery was catheterized up to the radicular branch. Further selective catheterization was performed up to the midline. However, further super-selective catheterization did not allow passage through the sulcal artery. Therefore, the endovascular procedure was terminated, and a surgical procedure was planned and performed 6 days later.

The lesion was approached via a C3 somatectomy. Surgery was performed with the aid of electrophysiological monitoring (motor evoked potentials, MEPs). After a midline durotomy in the vertical direction, we identified the anterior spinal artery and the right radicular artery of $\mathrm{C} 2$ with the aneurysm just left of the midline. Dissection of the arteries was very difficult due to the scarring of the arachnoid, which was yellowish as a result of the SAH. Using indocyanine green (ICG), we identified the pedicle and applied a clip (Figure 2C,D). Using a micro-Doppler and ICG, we confirmed the complete exclusion of the fistula. MEPs were stable throughout the procedure. We used an allograft with a titanium plate and bicortical screws to stabilize the cervical spine (Figure 2E). The postoperative course was uneventful. A follow-up lumbar puncture showed normal pressure, and the patient was improving; therefore, there was no need for further shunt surgery. The patient was transferred to a physical therapy department. Nine months after the SAH, the patient complained only of slight 
vertigo and right side hypacusis. An X-ray 20 months after the surgery showed complete $\mathrm{C} 3-\mathrm{C} 5$ fusion (Figure 2F). The patient showed no further symptoms of hydrocephalus, and her ventricles remained narrow on follow-up CT scans.
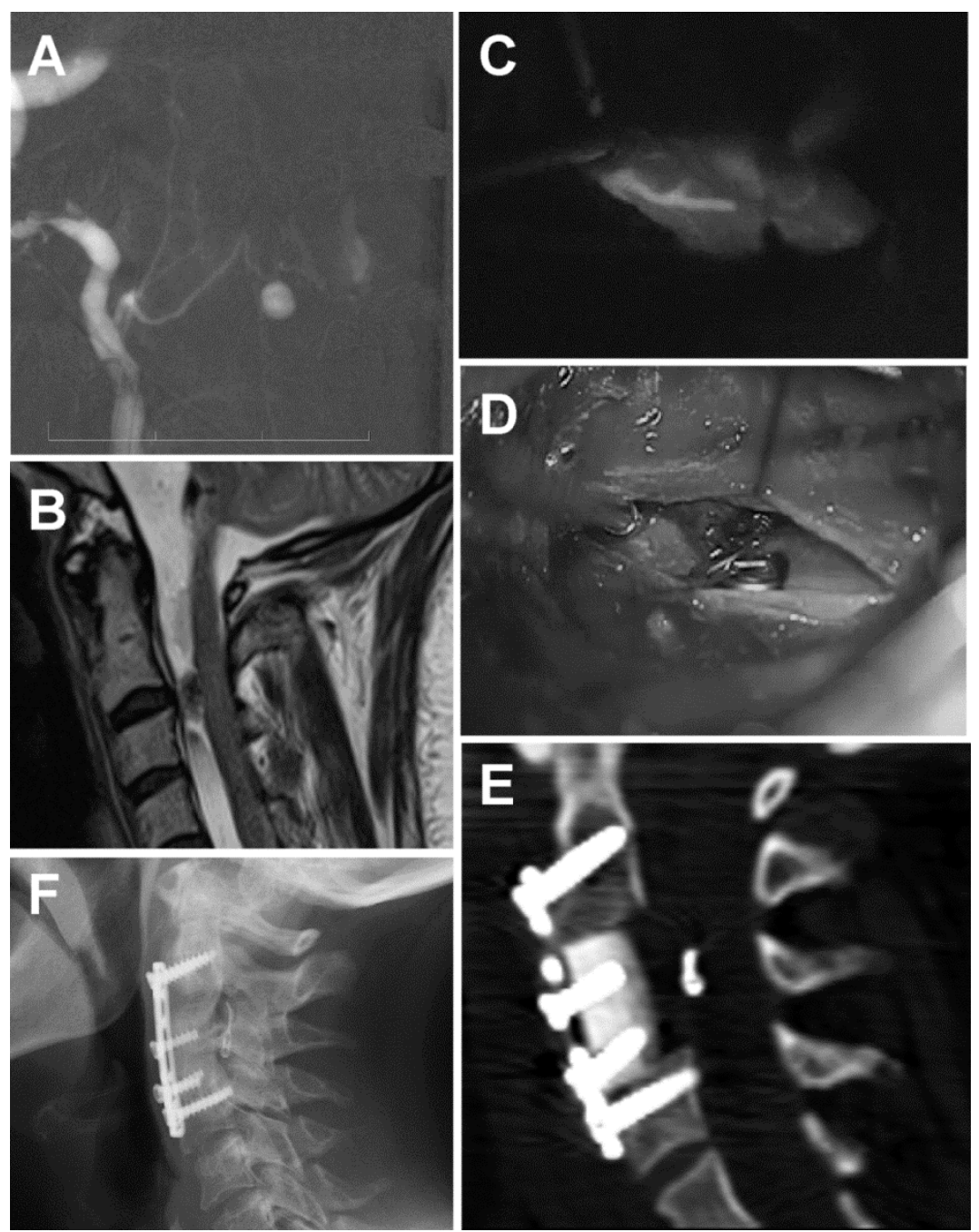

Figure 2. Spinal aneurysm associated with a ventral cervical arterio-venous (AV) fistula (A) AV fistula associated with an aneurysm displayed with a super-selective digital subtraction angiography (DSA). (B) Sagittal T2W MRI showing a lesion ventral to the spinal cord at the C2/3 level. (C) Perioperative indocyanine green (ICG) showing the pedicle feeding a type IVA ventral AV fistula from the anterior spinal artery. (D) Perioperative microscopic image after clipping the AV fistula. (E) Tibial bone allograft with a titanium plate and bicortical screws after C3 somatectomy. The clip is visible in front of the spinal cord, just in the middle of the approach. (F) The X-ray image shows the complete fusion of the allograft with the cervical bodies.

\section{Discussion}

Aneurysmal SAH is associated with high mortality and morbidity [1,9]. However, in about $15 \%$ of cases, no vascular intracranial lesion is discovered on initial DSA. Non-aneurysmal non-PMSAH tend to have a similar clinical course to an aneurysmal SAH and have a significant risk of an underlying cause of hemorrhage [10]. Up to 2004, there have been 17 cases of spinal AVFs associated with SAH.

In our case, the patient presented with massive posterior fossa SAH and hemocephalus due to a ruptured aneurysm associated with a ventral cervical spine fistula. However, only a PCom aneurysm was diagnosed on the initial emergency CT angiography and was mistakenly considered to be the 
source of bleeding. A similar scenario was described by Vates et al. [11]. However, perioperative findings suggested that the aneurysm was unruptured (no thrombus or brain adherence to the sac, irregularities of the sac, or translucent aneurysm wall) blood from the SAH extended far down the spinal canal. This led to further diagnostic procedures, including repeated DSAs. Akcakaya et al. found that there is approximately a $5 \%$ chance of diagnosing an underlying cause (aneurysm) of SAH on subsequent DSA. The same authors used spinal MRIs in patients with non-aSAH after the second DSA was negative. In such cases, they present positive findings on spinal MRIs in $3.7 \%$ of cases between 2 weeks to 12 months after the SAH [3]. Germans et al. do not recommend routine radiological investigation of the spinal axis of patients with non-aneurysmal SAH [12]. However, in our case, retrospectively, the distribution of SAH was indicative of a spinal lesion (Figure 1B), and the MRI could have perhaps been performed earlier, even after the first DSA.

The cause of SAH was an aneurysm associated with an AV fistula at the cervical C23 level. Several case reports and miniseries describe patients with ruptured AV fistulas who presented with SAH. They are summarized in Table 1. Our case was a ventral intradural AV fistula associated with an aneurysm, type IV, based on the classical Heros classification or type III fistula, according to the modified classification of Kim and Spetzler [7,8]. Ventral AV fistulas are very rare, accounting for only $6 \%$ of all AVFs. They predominantly occur in younger patients and are most often found at the conus medullaris and cauda equina. Our patient was 58 years old at the time of presentation, and the lesion was located in the cervical level. Koch et al. presented a very similar case, in which the SAH was caused by an AV fistula at the L4 level [13]. Hemorrhage is more common (20-40\%) in these AVFs due to a higher flow rate. In rare cases, the aneurysm may even be intramedullary, and, in case of rupture, may cause an intramedullary hematoma [14]. Ventral AVFs can be divided into three subtypes: A, B, and C. Our patient harbored an A type of fistula, which is characterized by a single low flow shunt with characteristics similar to dorsal intradural AVFs. In our case, the AVF was associated with an aneurysm, the cause of the SAH. Both surgical and endovascular treatments have been used for the treatment of these fistulas, as shown in Table 1. The type of treatment has usually been made after a detailed analysis of the angioarchitecture of the vascular lesion. Microsurgery is the treatment of choice in the subtypes A and B because EVT is often limited by ASA involvement, which is difficult to catheterize and navigate $[15,16]$. This is exactly what we experienced in our case during the EVT procedure. Concerning the surgical approach, the location of the aneurysm and the fistula required a C3 somatectomy to gain the space required for proper dissection of the lesion. This approach for a ventral AVF was probably first described by Hida et al. [16] DSA, together with MRI, were very helpful for planning the approach. The dural opening was in the midline above the anterior spinal artery. Perioperative ICG proved to be a useful tool for demarcation and identification of the fistula and aneurysm as the post-hemorrhage scarring and coloring around the lesion made dissection difficult. ICG was later also used to confirm the patency of the ASA after clipping the feeder. ICG with different flow mapping may be even more essential for complex spinal AVMs [4]. Another alternative may be perioperative DSA, as advocated by Ogawa et al. [17]. During surgery, we made sure that the ASA was preserved [7]. The procedure was performed under MEPs monitoring, which we consider a necessity for performing safe surgery of spinal AVMs.

The main disadvantage of the ventral approach is the necessity of resecting one or more vertebral bodies. In our case, only a one-level somatectomy was required to obtain an adequate approach, due to small fistula size. Markert et al. propose an alternative, an extreme lateral approach to reach ventral AV lesions without the need for resecting vertebral bodies [18]. However, they described this approach for a fistula at the C1/2 level, which would require a transoral route for the ventral approach. This would be associated with an even higher risk of cerebrospinal fluid (CSF) leak and infection. The ventral approach, in our case, was elegant, and the allograft fused very well without any functional deficit for the patient. For larger lesions requiring multiple somatectomies or lesions located at the levels with a more complicated ventral approach (upper thoracic segments), the extreme lateral approach is a reasonable alternative. Further technological developments, such as in neuroendoscopy, may provide 
additional tools for obtaining an excellent view as well as adequate space via a minimally invasive approach [17].

Non-aneurysmal non-PMSAH present with similar complications as aneurysmal SAH. In our case, the patient suffered from early hydrocephalus. In patients with non-aneurysmal SAH, the risk of early hydrocephalus is around $30 \%$, with $10 \%$ eventually requiring shunt placement [19]. According to these authors, early hydrocephalus was also associated with an unfavorable outcome. In our case, the patient suffered from acute hydrocephalus and required repeated CSF shunting. Throughout the treatment, she experienced some typical complications associated with CSF drainage, such as malposition with revisions, eventually leading to meningitis and shunt removal. Fortunately, the hydrocephalus resolved spontaneously without causing any additional morbidity.

Table 1. Literature summary of spinal arterio-venous (AV) fistulas which presented with spontaneous subarachnoid hemorrhage (SAH).

\begin{tabular}{|c|c|c|c|c|c|}
\hline Author & Year & Patient Age & Spine Level & Outcome & Treatment \\
\hline Inoue et al. [20] & 2019 & 59 & High Cervical & mRS5 & refused treatment \\
\hline Liu et al. [21] & 2008 & 26 & High Cervical & mRS0 & surgical resection \\
\hline Akter et al. [22] & 2011 & 68 & High Cervical & N/A & surgical resection \\
\hline Akter et al. & 2011 & 53 & High Cervical & N/A & surgical resection \\
\hline Akter et al. & 2011 & 56 & Cervical & N/A & surgical resection \\
\hline Akter et al. & 2011 & 60 & Thoracic & N/A & surgical resection \\
\hline Hayashi et al. [23] & 2004 & 67 & Cervical & mRS0 & embolization \\
\hline Kai et al. [24] & 2005 & 54 & High Cervical & mRS1 & surgical resection \\
\hline Kai et al. & 2005 & 56 & High Cervical & mRS1 & surgical resection \\
\hline Fernandéz et al. [25] & 2008 & 5 & High Cervical & mRS1 & surgical resection \\
\hline Poisson et al. [26] & 2008 & 8 months & Low thoracic & mRS3 & embolization \\
\hline Lv et al. [27] & 2012 & 17 & High Cervical & mRS2 & embolization \\
\hline Ohmori et al. [28] & 2005 & 42 & Low thoracic & mRS0 & surgical resection \\
\hline Bagherpour et al. [29] & 2016 & 14 & Conus medullaris & mRS0 & surgical resection \\
\hline Ohba et al. [30] & 2011 & 55 & High Cervical & mRS1 & surgical resection \\
\hline Vates et al. [11] & 2001 & 65 & Conus medullaris & mRS4 & surgical resection \\
\hline Kominami et al. [31] & 1996 & 12 & High Cervical & N/A & embolization \\
\hline Alshekhlee et al. [32] & 2011 & 57 & High Cervical & mRS4 & embolization \\
\hline Hida et al. [16] & 2002 & 58 & High Cervical & N/A & surgical resection \\
\hline Hida et al. & 2002 & 59 & High Cervical & N/A & surgical resection \\
\hline Hida et al. & 2002 & 62 & High Cervical & N/A & surgical resection \\
\hline Hida et al. & 2002 & 62 & Low Cervical & N/A & surgical resection \\
\hline Hida et al. & 2002 & 34 & Low Cervical & N/A & combination \\
\hline Wakai et al. [33] & 1992 & 8 & Low Cervical & mRS1 & surgical resection \\
\hline
\end{tabular}

\section{Conclusions}

Spinal AV fistulas are rare causes of SAH. Accurate diagnosis and microsurgery are the keys to successful treatment of this type of a ventral AV fistula, while risk factors associated with this severe non-aneurysmal SAH should be anticipated and treated to improve the probability of a good outcome in these patients. 
Author Contributions: A.H. treated the patient, collected the data, and wrote the manuscript. F.C. performed the angiography part of the study, edited the manuscript. M.S. treated the patient, supervised the whole manuscript, performed the final review and editing. J.L. prepared a literature review of AV fistulas with SAH (Table 1) and corrected the manuscript as a native speaker. All authors have read and agreed to the published version of the manuscript.

Funding: This research was funded by a grant No. 17-32872A from the Czech Health Research Council (AZV ČR), by the project no. LQ1605 from the National Program of Sustainability II (MEYS CR) and by the project FNUSA-ICRC no. CZ.1.05/1.1.00/02.0123 (OP VaVpI), and by a grant no. IGA KZCR-2017-1-13 by the Internal Grant Agency of the Krajská zdravotní.

Conflicts of Interest: The authors declare no conflict of interest.

\section{References}

1. van Dijk, E.J.; Hupperts, R.M.; van der Jagt, M.; Bijvoet, H.W.; Hasan, D. Diagnosis of perimesencephalic nonaneurysmal subarachnoid hemorrhage with computed tomography. J. Stroke Cerebrovasc. Dis. 2001, 10, 247-251. [CrossRef] [PubMed]

2. Konczalla, J.; Kashefiolasl, S.; Brawanski, N.; Senft, C.; Seifert, V.; Platz, J. Increasing numbers of nonaneurysmal subarachnoid hemorrhage in the last 15 years: Antithrombotic medication as reason and prognostic factor? J. Neurosurg. 2016, 124, 1731-1737. [CrossRef] [PubMed]

3. Akcakaya, M.O.; Aydoseli, A.; Aras, Y.; Sabanci, P.A.; Barburoglu, M.; Alkir, G.; Sencer, A.; Sencer, S.; Aydin, K.; Kiris, T.; et al. Clinical Course of Non-Traumatic Non-Aneurysmal Subarachnoid Hemorrhage: A Single Institution Experience over 10 Years and Review of the Contemporary Literature. Turk. Neurosurg. 2017, 27, 732-742. [PubMed]

4. Rangel-Castilla, L.; Russin, J.J.; Zaidi, H.A.; Martinez-Del-Campo, E.; Park, M.S.; Albuquerque, F.C.; McDougall, C.G.; Nakaji, P.; Spetzler, R.F. Contemporary management of spinal AVFs and AVMs: Lessons learned from 110 cases. Neurosurg. Focus 2014, 37, E14. [CrossRef]

5. Hejčl, A.R.T.; Sameš, M. Our experience with lateral supraorbital approach in surgery of intracranial aneurysms. Ceska Slovenska Neurologie Neurochirurgie 2012, 75, 203-207.

6. Hernesniemi, J.; Ishii, K.; Niemela, M.; Smrcka, M.; Kivipelto, L.; Fujiki, M.; Shen, H. Lateral supraorbital approach as an alternative to the classical pterional approach. Acta Neurochir. Suppl. 2005, 94, 17-21.

7. Kim, L.J.; Spetzler, R.F. Classification and surgical management of spinal arteriovenous lesions: Arteriovenous fistulae and arteriovenous malformations. Neurosurgery 2006, 59, S195-S201. [CrossRef]

8. Heros, R.C.; Debrun, G.M.; Ojemann, R.G.; Lasjaunias, P.L.; Naessens, P.J. Direct spinal arteriovenous fistula: A new type of spinal AVM. Case report. J. Neurosurg. 1986, 64, 134-139. [CrossRef]

9. Lantigua, H.; Ortega-Gutierrez, S.; Schmidt, J.M.; Lee, K.; Badjatia, N.; Agarwal, S.; Claassen, J.; Connolly, E.S.; Mayer, S.A. Subarachnoid hemorrhage: Who dies, and why? Crit. Care 2015, 19, 309. [CrossRef]

10. Kapadia, A.; Schweizer, T.A.; Spears, J.; Cusimano, M.; Macdonald, R.L. Nonaneurysmal perimesencephalic subarachnoid hemorrhage: Diagnosis, pathophysiology, clinical characteristics, and long-term outcome. World Neurosurg. 2014, 82, 1131-1143. [CrossRef]

11. Vates, G.E.; Quiñones-Hinojosa, A.; Halbach, V.V.; Lawton, M.T. Conus perimedullary arteriovenous fistula with intracranial drainage: Case report. Neurosurgery 2001, 49, 457-461. [PubMed]

12. Germans, M.R.; Coert, B.A.; Majoie, C.B.; van den Berg, R.; Verbaan, D.; Vandertop, W.P. Spinal axis imaging in non-aneurysmal subarachnoid hemorrhage: A prospective cohort study. J. Neurol. 2014, 261, 2199-2203. [CrossRef] [PubMed]

13. Koch, C.; Gottschalk, S.; Giese, A. Dural arteriovenous fistula of the lumbar spine presenting with subarachnoid hemorrhage. Case report and review of the literature. J. Neurosurg. 2004, 100, 385-391. [PubMed]

14. Matsui, T.; Taniguchi, T.; Saitoh, T.; Kamijoh, K.; Nakamura, T.; Yamashita, A.; Takayanagi, S.; Sakamoto, M.; Ishikawa, T. Hematomyelia caused by ruptured intramedullary spinal artery aneurysm associated with extramedullary spinal arteriovenous fistula-Case report. Neurol. Med. Chir. (Tokyo) 2007, 47, 233-236. [CrossRef] [PubMed]

15. Spetzler, R.F.; Detwiler, P.W.; Riina, H.A.; Porter, R.W. Modified classification of spinal cord vascular lesions. J. Neurosurg. 2002, 96, 145-156. [CrossRef] 
16. Hida, K.; Iwasaki, Y.; Ushikoshi, S.; Fujimoto, S.; Seki, T.; Miyasaka, K. Corpectomy: A direct approach to perimedullary arteriovenous fistulas of the anterior cervical spinal cord. J. Neurosurg. 2002, 96, 157-161. [CrossRef]

17. Mansour, A.; Endo, T.; Inoue, T.; Sato, K.; Endo, H.; Fujimura, M.; Tominaga, T. Clipping of an anterior spinal artery aneurysm using an endoscopic fluorescence imaging system for craniocervical junction epidural arteriovenous fistula: Technical note. J. Neurosurg. Spine 2019, 26, 1-6. [CrossRef]

18. Markert, J.M.; Chandler, W.F.; Deveikis, J.P.; Ross, D.A. Use of the extreme lateral approach in the surgical treatment of an intradural ventral cervical spinal cord vascular malformation: Technical case report. Neurosurgery 1996, 38, 412-415. [CrossRef]

19. Konczalla, J.; Platz, J.; Schuss, P.; Vatter, H.; Seifert, V.; Guresir, E. Non-aneurysmal non-traumatic subarachnoid hemorrhage: Patient characteristics, clinical outcome and prognostic factors based on a single-center experience in 125 patients. BMC Neurol. 2014, 14, 140. [CrossRef]

20. Inoue, T.; Endo, T.; Sato, K.; Fesli, R.; Ogawa, Y.; Fujimura, M.; Matsumoto, Y.; Tominaga, T. Massive Intramedullary Hemorrhage After Subarachnoid Hemorrhage in Patient with Vertebrovertebral Arteriovenous Fistula. World Neurosurg. 2019, 129, 432-436. [CrossRef]

21. Liu, C.L.; Su, Y.C.; Chen, C.C.; Chong, C.F.; Wang, T.L. Ruptured cervical arteriovenous fistulas presenting with subarachnoid hemorrhage and quadriplegia: An uncommon case. Am. J. Emerg. Med. 2008, 26, 249.e1-2. [CrossRef] [PubMed]

22. Akter, M.; Hirai, T.; Kitajima, M.; Kai, Y.; Morioka, M.; Sasao, A.; Utsunomiya, D.; Uetani, H.; Korogi, Y.; Yamashita, Y. Type 1 perimedullary arteriovenous fistula with subarachnoid hemorrhage: Utility of contrast-enhanced 3D gradient-echo technique. Magn. Reson. Med. Sci. 2011, 10, 143-147. [CrossRef] [PubMed]

23. Hayashi, K.; Takahata, H.; Nakamura, M. Two cases of spinal arteriovenous malformation presenting with subarachnoid hemorrhage. No Shinkei Geka 2004, 32, 605-611. [PubMed]

24. Kai, Y.; Hamada, J.; Morioka, M.; Yano, S.; Mizuno, T.; Kuratsu, J. Arteriovenous fistulas at the cervicomedullary junction presenting with subarachnoid hemorrhage: Six case reports with special reference to the angiographic pattern of venous drainage. AJNR Am. J. Neuroradiol. 2005, 26, 1949-1954. [PubMed]

25. Alonso Fernández, L.; Nzau, M.; Ventureyra, E. Spinal intradural arteriovenous fistula with unusual presentation: Case report and literature review. Childs Nerv. Syst. 2008, 24, 1349-1353. [CrossRef] [PubMed]

26. Poisson, A.; Vasdev, A.; Brunelle, F.; Plauchu, H.; Dupuis-Girod, S.; French Italian HHT network. Acute paraplegia due to spinal arteriovenous fistula in two patients with hereditary hemorrhagic telangiectasia. Eur. J. Pediatr. 2009, 168, 135-139. [CrossRef]

27. Lv, X.; Li, Y.; Yang, X.; Jiang, C.; Wu, Z. Endovascular embolization for symptomatic perimedullary AVF and intramedullary AVM: A series and a literature review. Neuroradiology 2012, 54, 349-359. [CrossRef]

28. Ohmori, Y.; Hamada, J.I.; Morioka, M.; Yoshida, A. Spinal aneurysm arising from the feeding pedicle of a thoracic perimedullary arteriovenous fistula: Case report. Surg. Neurol. 2005, 64, 468-470. [CrossRef]

29. Bagherpour, A.N.; Rodriguez, G.J.; Moorthy, C.; Trier, T.T.; Maud, A. Combined surgical and endovascular treatment of complex high-flow conus medullaris arteriovenous fistula associated with Parkes Weber syndrome: Case report. J. Neurosurg. Spine 2016, 25, 234-238. [CrossRef]

30. Ohba, S.; Onozuka, S.; Horiguchi, T.; Kawase, T.; Yoshida, K. Perimedullary arteriovenous fistula at the craniocervical junction-Case report. Neurol. Med. Chir. (Tokyo) 2011, 51, 299-301. [CrossRef]

31. Kominami, S.; Liu, Y.; Alvarez, H.; Rodesch, G.; Coubes, P.; Lasjaunias, P. A case of vertebrovertebral arteriovenous fistula presenting with subarachnoid haemorrhage. A case report. Interv. Neuroradiol. 1996, 2, 229-233. [CrossRef]

32. Alshekhlee, A.; Edgell, R.C.; Kale, S.P.; Kitchener, J.; Vora, N. Endovascular therapy of a craniocervical pial AVF fed by the anterior spinal artery. J. Neuroimaging 2013, 23, 102-104. [CrossRef]

33. Wakai, S.; Inoh, S.; Iwanaga, H.; Nagai, M.; Sato, T.; Izumi, J. Successful surgical obliteration of a huge intradural arteriovenous fistula of the spinal cord in a child. Childs Nerv. Syst. 1992, 8, 347-350. [CrossRef]

(C) 2020 by the authors. Licensee MDPI, Basel, Switzerland. This article is an open access article distributed under the terms and conditions of the Creative Commons Attribution (CC BY) license (http://creativecommons.org/licenses/by/4.0/). 